\title{
Hysterectomies and Violation of Human Rights: Case Study from India
}

\author{
Bharath Bhushan Mamidi ${ }^{1, *}$, Venkat Pulla ${ }^{2}$ \\ ${ }^{1}$ Centre for Action Research and People's Development, 8-3-228/267, Rahmath Nagar, Hyderabad, 500045, India \\ ${ }^{2}$ School of Humanities and Social Sciences, Charles Sturt University, Wagga Wagga, NSW, 2678, Australia vpulla@csu.edu.au; \\ dr.venkat.pulla@gmail.com \\ *Corresponding Author: mbbhushan@gmail.com
}

\begin{abstract}
Patriarchal values at one level and gender bias at the other are pervasive in south Asian countries. Even after six decades of planned development, the incidence of women's human rights in general and in particular sexual and reproductive health rights (SRHR) are being violated for different motives by different sections of the Indian society. Our studies and resultant social action commenced when we heard about women already experiencing poverty and who were further robbed off their bodies and life by conniving mechanisms in society through abuse of health insurance schemes. Most of these rural women were cheated to undergo hysterectomy due to their illiteracy and their vulnerability. Narratives and the accounts of the rural poor women victims clearly identify their poverty, illiteracy and status in the overall social fabric of the Indian society that went against them. These unwanted hysterectomies in Medak district in India highlighted the role of insurance, gender bias, lack of ethical conduct in the medical profession.
\end{abstract}

Keywords Civil Society, Ethics in Medicare, Forced Hysterectomies, Gender, Governance, Heath Insurance, Human Rights, Safety Nets

\section{Is development a threat to rights of the poor?}

\subsection{Introduction}

This study is about women and their sexual and reproductive health rights (SRHR) that the paper asserts are being continuously violated in the Indian society. News of women already experiencing poverty were further cheated by conniving medical practitioners alerted us to undertake a comprehensive study of the local issues in a district called Medak in India. This is a district where the doyen of women's power and India's Prime Minister Indira Gandhi Copyright (C) 2013 Horizon Research Publishing did get elected during the country's only emergency. Illiteracy and vulnerability of rural women exacerbated the pathetic scams around state and private health insurance schemes in this context and women underwent hysterectomy for no fault in most cases. We attempt to triangulate the findings with the narratives and observations of the volunteers of the non government organization called the Centre for Action Research and People's Development; the narratives of the poor and Lambada women victims across the backdrop of discourse on poverty and the governance or lack of governance of these programmes.

Women's human rights in general and in particular women's SRHRs are violated for different motives by different agencies including governments. High incidence of sterilizations among women in pre-menopausal stage often conducted in camps to meet government targets in Andhra Pradesh state of India exposed women to risks of infections (Srivastava, 2012). Median age at sterilization is lowest at 23.3 years in Andhra Pradesh against the national median age of 25.5 years, according to National Family Health Survey (NFHS-3, 2005-06). Forced sterilizations and early menopause is very high in parts of India. Early menopause is highest in Andhra Pradesh with $31 \%$ of women with menopause aged between 30 and 49 years against the national average of around $18 \%$ in India, according to the second National Family Health Survey - 1998-1999.Forced sterilizations of women in Uzbekistan and Namibia are reported to have become part of the population control programme (Colekessian, 2013). Young women living with HIV/AIDS, young women and girls with disabilities and indigenous women (among others) in Uzbekistan, and women living with HIV/AIDS in Namibia are victims of forced sterilizations. Uzbekistan government programme 'Improvement of Mother and Child Health Services programme' supported by UNICEF and the European Union aimed to "improve quality of care for mothers and children, and promote health-seeking practices among families and communities", is reported distorting reproductive health goals into population control including with fixed monthly quotas for the physicians to curb fertility rates through forced 
sterilizations. It is also seen as part of protecting maternal health as less of them die. Violence against women, violation of human rights and women's SRHRs are also reported widely from India (Mamidi \& Mamidi, 2007; Kameswari \& Vinjamuri, 2013; Prakasamma 2002; Prasad \& Raghavendra, 2012). Violation of women's SRHRs is widespread and is increasing with government supported health insurance schemes that reimburse money to private hospitals performing surgeries for women from poor households. Studies indicate growing importance of private sector in healthcare (Prasad \& Raghavendra, 2012; Nagulapalli \& Rokkam, 2013) and concerns of private sector making healthcare into business and patients into consumers without any protection for their rights. Health insurance schemes are also used by ruling parties for political mileage.

Development programmes run by the government or private agencies with support of the state, safety nets and welfare measures could become serious threat to the human rights if governance measures are weak with regard to the framework in which business operates. This is a challenge in several developing countries and by the same token the Millennium Development Goals (MDGs) could be jeopardized if the governance is weak and laden with corrupt practices. Several studies highlight that human rights discourse ought to sit beyond economic indicators of progress and ensure well being.

\subsection{Methodology}

This paper examines the violation of women's SRHRs and the growing incidence of coerced hysterectomies with the introduction of state sponsored community health insurance scheme involving private hospitals. Review of literature presents the widespread nature of forced hysterectomies across the country and the role of private hospitals in health insurance. Detailed analysis of the background of affected women is based on field research conducted by Centre for Action Research \& People's Development (CARPED) covering 728 hysterectomised women in Kowdipally mandal of Medak district in 2005. Growing incidence of hysterectomies among younger women is discussed based on comparison of CARPED data with another field study conducted by Life-HRG covering 171 affected women in Munipally mandal of the same district after introduction of community health insurance scheme by the government of Andhra Pradesh. Qualitative data on the adverse impact of hysterectomies is collected for this paper through interviews of affected women in 2011. Discussion on civil society response to growing incidence of coerced hysterectomies and policy changes is based on interviews with representatives of NGOs and secondary data. Names of the respondents have been changed to ensure anonymity of the affected women.

Violation of Women's Health Rights and MDGs
Protection and promotion of health, particularly of the poor, forms direct focus of four out of eight MDGs. Women's health is central to goal 1 to 'eradicate extreme poverty and hunger,' goal 4 to 'reduce child mortality', goal 5 to 'improve maternal health' and goal 6 to 'combat HIV/AIDS, malaria and other diseases'. Health and women's rights and gender mainstreaming is cross-cutting and cross -sectoral with regard to the eight MDGs. Pursuance of MDGs also requires to ensure rights of women in accordance with the Convention on the Elimination of All Forms of Discrimination against Women. Beijing Declaration 1995 further emphasized that women's empowerment and equal participation were essential for development. Mainstreaming gender in MDGs is stressed through complementary and additional gender-sensitive indicators for each of the MDG targets developed by the United Nations Economic and Social Commission for Asia and the Pacific. Further, the UNIFEM made recommendations for mainstreaming gender in each goal. The Universal Declaration of Human Rights assures right to medical care and a human right to "special care and assistance" (art. 25) for mothers and their children. Women's right to make choices about her body and reproductive health are upheld by the International Covenant on Civil and Political Rights (Article 7); the Convention on the Elimination of All Forms of Discrimination Against Women (Articles 10h, 12, 16e, Gen. Rec. 19); and the Beijing Declaration and the Platform for Action (Women and Health, para. 94).

Studies indicate that MDGs could become detrimental to the poor with the introduction of new measures or renewed emphasis on 'development' schemes that are devoid of the responsibility to protect the human rights of the vulnerable sections of the society. Development focused on reducing instead of eliminating poverty, while accelerates growth, intensifies exclusion of the vulnerable groups (UNHR, 2008). It is observed that "ambiguous wording of the target has allowed some countries in their MDG reports to list policies that prima facie violate human rights", for instance in improving access to shelter to urban poor also includes slum clearance (UNHR, 2008).Exclusion of remote rural areas and urban poor, indigenous people, women and children of deprived communities from development goals is an imminent threat of the development goals that have not been adapted to address inequalities, poverty and vulnerability of particular groups in the local context. Threats to human rights inherent in the MDGs have been cautioned quite early by international agencies. The 2007 global snapshot at the halfway point of the Millennium Development Goals revealed critical gaps with continued deaths of half a million women from preventable complications in pregnancy or childbirth, deeply troubling child mortality rates in Southern Asia and sub-Saharan Africa, preventive measures being inadequate to keep pace with HIV/AIDS epidemic, and Governments not honoring their commitments. Compelling contradictions are reflected by, United Nations High Commissioner for Human Rights, Louise Arbour reflects 
that the purposes of the Millennium Declaration cannot be disembodied from the human rights context (UNHR, 2008).

Freedom of choice and informed decisions of women in matters affecting their right to health, regulation of fertility, and the right of access to appropriate healthcare services is part of human rights. Article 12 of CEDAW recognizes a general prohibition on discrimination against women in the provision of health services and a special legal obligation on States to "ensure to women appropriate services in connection with pregnancy." The obligation to respect a women's right to health requires that States parties should not restrict women's access to health services or to the clinics that provide those services "irrespective of their marital status, on a basis of equality of men and women, of human rights and fundamental freedoms in the political, economic, social, cultural, civil or any other field". The Committee on Economic, Social and Cultural Rights has stated that "women and men have the freedom to decide if and when to reproduce and the right to be informed and to have access to safe, effective, affordable and acceptable methods of family planning of their choice." Coerced hysterectomies involving surgically removing or disabling reproductive organs without full or informed consent, constitutes violence against women. Hysterectomies without consent and full knowledge of the consequences as well as information of alternative relief measures are manipulating her body against her will.

\section{State and Market Driven Health Insurance Scheme}

Health is often the most important and only asset and hope for survival of the poor. Any threat, loss, debility in health erodes the ability to earn enough to feed oneself and meet costs of treatment of illness. Illness and costs on healthcare costs put lives of the household at risk and push them into further impoverishment. Besides, poor access to healthcare in India, there are also inequities of varied nature viz., intra-state, rural- urban, vulnerable communities, women, etc. Indian health care is poorer than Sri Lanka and Bangladesh with comparable per capita incomes. Total health expenditure on health from all sources in India was Rs. 1,337,763 million constituting $4.25 \%$ Gross Domestic Product (GDP) during 2004-05 of which the share of private sector was $78.05 \%$ of which households contributed significant portion at $71.13 \%$ towards expenditure on inpatient, outpatient care, family planning, and immunization etc., according to National Health AccountsIndia (MHFW, 2009, p.2). Out of pocket expenditure to households is high forcing the households into severe financial crunch in case of critical illness.

\subsection{Private Insurance}

Individual premium to insurance agency for meeting unforeseen medical expenses due to illness or accidents is relatively new in India. Such private Insurance in health sector accounts for $3.1 \%$ of total health expenditure and a substantial amount of health expenditures (presumably curative care) in India is not covered by insurance schemes (MFHW, 2005). Households spend $69 \%$ of the total health expenditure followed by $2 \%$ from others in the private sector, the different branches of the government (Central, State and local) as well as Public Sector Undertakings contributing about $26 \%$, social insurance $2.36 \%$, and private insurance $0.70 \%$ (NHA 2005).

Growth of private players in health insurance sector is promoted by liberalization since 2000 . Health insurance premium registered $1142 \%$ from Rs 10020 million in 2002-03 to Rs 114,500 million in 2010-11 although health insurance penetration in India as such is very low.

\subsection{State Sponsored Insurance}

State sponsored health insurance schemes are considered 'effective instrument' to address inequalities in access to health insurance by providing basic health cover to un-insured poor so as to receive services from the best hospitals on par with the well to do. Important initiatives of this model in India with government paying the premium on behalf of the poor households to insurance companies include the Central government sponsored Rashtriya Bhima Suraksha Yojana (RSBY) by the Ministry of Labour and Employment launched in 2003, Rajiv Aarogyasri Community Health Insurance Scheme popularly known as Aarogyasri in Andhra Pradesh, Vajpayee Aarogyasri in Karnataka and the Kalaignar scheme in Tamil Nadu which support hospitalization care. These models provide health insurance coverage for below poverty line (BPL) families from Rs 30,000 (RSBY) to Rs 150,000 (Rajiv Aarogyasri) per family per year for large number of diseases that require hospitalization. RSBY scheme, implemented across the states, has $75 \%$ contribution from central government and $25 \%$ by state government.

Involving insurance companies in increasing access to healthcare for the poor is a fast growing alternative in India. These alternative models claim impressive numbers of making healthcare possible to a large population despite being poor. RSBY beneficiaries alone include 5,456,736 cases up to 17 June 2013. However, there are inequalities with rural poor having lesser as hospitals are concentrated in large towns and awareness among the vulnerable sections about the scheme is poor (Choudhury, 2012). Besides, there are several undesirable practices and corruption as well in RSBY. There are reports of corruption and abuse of RSBY resulting in violation of human rights across the states also (Yadavar, 2013).

Rajiv Aarogyasri model is briefly discussed as the paper examined violations of human rights with focus on women's sexual and reproductive health rights in Andhra Pradesh.

Aarogyasri, of Government of Andhra Pradesh (GOAP) launched on April 1, 2007 is based on public private partnership comprising the insurance company, private hospitals and the state agencies. It is implemented through 
Aarogyasri Health Care Trust (ACHT) which provides financial assistance to below poverty line (BPL) families to meet the catastrophic health needs by availing quality medical treatment for serious ailments. Prior to the Aarogyasri, a section of the poor have been assisted to meet hospitalization needs through Chief Minister's Relief Fund (CMRF). The CMRF assisted 55,361 cases costing Rs 1685 million between May 2004 and June 2007.

Under Aarogyasri BPL families are entitled hospitalization costs up to Rs. 150,000 per family per year. Around $87 \%$ of the state population (23.3 million families out of 26.6 million families) have health coverage under the scheme. Insurance company pays the hospital bills, while government pays the premium of Rs 210 per household per annum to the insurance company for every enrolled BPL family. Estimates of BPL by Government of India are around $40 \%$ while state government data shows more than double (Yellaiah, 2013). Insurance company conducts medical camps through network hospitals across the state to create awareness and screen patients requiring healthcare. Altogether 35,713 medical camps were conducted from 1 April 2007 to 18 January 2013 and 1753,466 Surgeries/ Therapies were conducted (440,655 in Government hospitals and 1312,811 in Private hospitals) incurring a total of Rs. 47,230 million (Government hospitals Rs.10710 million and Private Rs.36520 million). There are wide inter-district variations with three districts together (Hyderabad, Krishna and Vishakapatnam) constituting $45.92 \%$ of total beneficiaries while remaining 20 districts account for around $54.08 \%$. Inequities in healthcare access continued with disadvantaged sections such as females, Scheduled Castes and Scheduled Tribes having lesser access (Nagulapalli \& Rokkam, 2013).

Aarogyasri started initially with 330 procedures was gradually extended to 938 procedures covered under the scheme. Since 2011 as many as 133 treatments/ procedures including discectomy, laminectomy \& hysterectomy were reserved for Government hospitals owing to civil society protests against misuse of the scheme. Aarogyasri being a state sponsored progarmme, the district authorities are also its associates in implementing the scheme and in mobilization of the patients. District Administration will help the Trust in effective implementation of the scheme in the district by conducting reviews with District Coordinator of the Trust and also in conducting health camps and for mobilization of the patients". The programme is hailed as a flagship programme of the government and the propaganda emphasizing the poor to avail freely the costliest health services by simply producing a BPL cards. The Aarogyasri website says "Patient need not pay even single pie for these services under the scheme. All that is required is carry your health card or white card along with medical record if any and approach Aarogya Mithra for registration and facilitation."

Aarogyasri has four major players:

- Aarogyasri Health Care Trust (AHCT) is responsible for oversight of the whole scheme and administrative functions including critical functions like fixation of prices for therapies, preauthorizations for treatments, managing contracts with insurer, empanelling and contracts with network of hospitals, approving claims, etc. The AHCT had two routes of implementation of the scheme till 2011 i.e., fund management done directly by the Trust; and transferring part of the fund to the insurer for management and claims payment.

- Insurance company bears risk and manages all back end insurance operations like claims processing, reimbursements to providers, and oversight of hospitals. The Insurer plays critical role in generating demand for the scheme by holding health camps across the state through network hospitals to enroll eligible beneficiaries.

- Network hospitals (380 network hospitals) are empanelled to serve the patients i.e., the BPL households.

- Aarogya Mithras are the primary contact with patients in the hospitals and are responsible for community outreach.

Available research on the role of insurance companies in health sector indicates that it is not all that healthy. Aarogyasri has been subject of several studies from the perspective of political economy and health economics (Mathews, 2012; Prasad \& Raghavendra, 2012; Shukla et. al, 2011; Vijay, 2012; Planning Commission of India, 2011; MHFW, 2005; Nagulapalli \& Rokkam, 2013). It is seen as a classical model of medical neo-liberalism promoting primarily interest of corporate healthcare industry focused on tertiary care through private hospitals, and transforming health industry into a means of generating rich electoral gains without addressing the root causes of highly neglected and underfunded state healthcare system (Prasad \& Raghavendra, 2012). Aarogyasri is also found to be a poor model on economic parameters. A study commissioned by Aarogyasri observed that "implementation of the scheme through the insurance mode is highly inefficient in terms of cost benefit ratio. Government hospitals were subject to discrimination under insurance mode" (Nagulapalli \& Rokkam, 2013).

There is mushrooming of corporate hospitals with Hyderabad city alone having 1200 healthcare facilities doing roaring business because of cash-rich Aarogyasri scheme, which is "pumping enough money into coffers of hospitals and patients on their beds" (Mathews, 2012). Corporate hospitals have grown into a pressure group demanding the government to add more procedures under the scheme. Andhra Pradesh Private Hospitals and Nursing Homes' Association and Andhra Pradesh Speciality Hospitals' Association demanded a $30 \%$ hike in reimbursements under Arogyasri and threatened to stop treating cases under Arogyasri from May 4, 2013 (The New Indian Express, 
2013).

National Commission on Macroeconomics and Health (NCMH) of Ministry of Health \& Family Welfare in 2005, National Health Accounts -India report in 2005, and High Level Expert Group for Universal Health Coverage of the Planning Commission, GOI in November 2011 also have been critical of the role of insurance sector for its misguided focus. The NCMH report cautioned against corporate hospitals indulging in overuse of diagnostic needs (MFHW 2005, p.229). The High Level Expert Group for UHC reported that approach of state sponsored health insurance schemes are entirely focused on hospital networks instead of primary care services and would "lead to inferior health outcomes and high health care cost inflation" (Planning Commission of India, 2011). Further, the financial risk protection to the BPL families is not substantial under these health insurance schemes- as they do not cover out-patient expenses, high frequency low cost treatments, and purchase of drugs by households (Planning Commission of India, 2011,p.123). The NCMH report observed that it is not sound to depend on insurance companies as no country relies on private insurance to resolve the problems of financial risk protection for the poor and the ill and that regulation is required to minimize some of the adverse impacts. It is of great concern as "the use of insurance companies to expend government resources is an unusual model and there are very few examples of this globally" (Planning Commission, 2011, p.111).

What is intended to be a life savior for the poor households could become life threatening if it is not regulated to ensure that it is used only for the stated objectives. The fears of abuse are serious since healthcare sector in India is considered the most corrupt service sector with private healthcare criticized for several unethical practices. MHFW 2005 report particularly observed that "the rate of hysterectomies being performed among young women is one example of the absence of ethical standards" (p.54). Market forces in private healthcare are of serious threat to the safety, right to health, reproductive and sexual health rights. The NCMH recommended that "if insurance and contracting the private sector are to be the new ways of expanding access and financing health, then it is essential that values of probity, nurturing of informed consumers and wider participation through good governance be ensured (MHFW 2005, p.55).

The following section examines the consequences of rampant abuse of the innovative models for making healthcare accessible to the poor and the responses of the civil society.

\section{Coerced Hysterectomies-Private Healthcare a Threat to Poor Women's SRHRs}

Hysterectomy is surgical removal of one or several of the organs: cervix, uterus or womb, and the fallopian tubes and both ovaries. It has severe adverse implications for the woman affecting her mental and physical health and wellbeing. Besides direct surgical risks, hysterectomised women suffer long -term physical and psychological effects including severe depression, increased risk of osteoporosis and heart disease. Side effects include surgically induced menopause causing "hormone imbalance" that require long term treatment. Women experience one or several of the side effects like depression, insomnia, weight loss, urinary incontinence, loss of sex drive, joint pains, heart palpitations, etc.

Hysterectomies include 'radical hysterectomy' (removal of cervix, upper vagina, lymph nodes, ovaries and fallopian tube), 'total hysterectomy' (removal of uterus and cervix) and 'subtotal hysterectomy' (removal of the uterus leaving the cervix intact). Removal of ovaries also increases the woman's risk of death by $40 \%$. It is a solution of last resort, when the surgical treatment is compulsory, due to long term adverse consequences to woman's health, longevity, and well being. When required it is performed after due medical examination that include hormone test, sonography or a pap smear to test for cancer.

Why indiscriminate hysterectomies- Insurance to ensure loss of womb?

"I went to the clinic because I had heavy bleeding during menstruation. The doctor did an ultrasound and said I might develop cancer. He rushed me into having a hysterectomy that same day," says Ms Sunita, aged about 25 in Rajasthan This was reported on BBC News. 1 .

Studies indicate that indiscriminate hysterectomies are primarily due to the greed of private hospitals interested in making money. Coercion of vulnerable women into hysterectomies is ensured through a structure of agents from the village to the private hospital in the town or cities. Magistrate Kundan Kumar of Samastipur district in Bihar investigating the scam of alarming number of 5503 hysterectomies out of 14,851 procedures conducted under RSBY between 2010 and 2012 in 16 empanelled hospitals found that hysterectomies constituted about $37 \%$ to more than $50 \%$ of all procedures in some hospitals. There were several false and bogus claims too2. Samastipur scam is not an exception of the abuses of RSBY. "Instead of resorting to conservative techniques, they go straightaway for surgeries which meant more money for them. I think there was basically a mad rush to earn as much money as possible to do unwarranted surgery", says Mr Kundan Kumar, District Magistrate of Samastipur district in Bihar (McGivering, 2013).

State sponsored healthcare for the poor through empanelled private hospitals has become a big business in

$1 \mathrm{http}: / /$ www.bbc.co.uk/news/magazine-21297606

2 The report revealed 717 cases of unwanted surgery, 124 cases of underage surgery, 320 cases of fleecing and 23 cases of non-surgery. Many beneficiaries claimed by the private hospitals could not be traced as the hospitals in some cases simply swiped their RSBY cards without conducting any surgery (Yadavar, 2013) 
several states of India. Mushrooming of private hospitals to perform several kinds of surgeries has become a major threat to the lives of the poor. Poor in the name of 'benefiting' and robbed of their bodies, often forced to become patients for ailments they don't have (Yadavar, 2013)

Most often the hysterectomised women have been operated in private hospitals. Rarely these surgeries were conducted in government hospitals. Studies conducted between 2002 and 2012 reveal that $88.89 \%$ to $95.32 \%$ of the hysterectomies were conducted in private hospitals with hardly 5 to $10 \%$ of these surgeries being done in government hospitals where the doctors have no personal gain. Forced hysterectomies have become more rampant after state sponsored insurance schemes have provided higher amounts to private hospitals for these surgeries. Studies on coerced hysterectomies in Chhattisgarh by HRLN indicate that "more often than not, doctors and private hospitals target SC, ST, and Below Poverty Line (BPL) women" (HRLN, 2013). The situation is similar in Andhra Pradesh according to Dr Prakasamma's study in Guntur and Mahbubnagar districts conducted in 2002 which revealed that $77.12 \%$ of the 153 hysterectomised women were illiterate and only $1.96 \%$ of the women had education beyond school.

Reports of poor people forced to become patients availing free surgeries supported by state health insurance schemes are plenty from Andhra Pradesh, Bihar, Chhattisgarh, and Rajasthan. The RSBY empanelled health facilities in Chhattisgarh resulted in unnatural spike in hysterectomies. It is reported that more than 7,000 hysterectomies were performed to reap around Rs 20 million the heavily subsidized health care coverage to BPLs under the RSBY scheme (HRLN, 2013). Private healthcare system is turning poor people of normal health into patients requiring serious surgeries that have long term adverse effects. The loot by private hospitals becomes simple by having network of local quacks who act as suppliers of poor patients for the unnecessary surgeries. Unqualified medical practitioners in rural areas, medical shop owners, even employees at government hospitals "act as agents who take patients to private clinics" for surgeries and get paid commission on referrals (Mamidi \& Mamidi 2005; Srivastava 2010; HRLN 2012; Yadavar 2013). There are several reports of victims complaining that "they only agreed to the operation after their doctors had scared them by telling them they were at risk of dying from cancer if they did not opt for surgical intervention" (HRLN, 2013). Studies in several regions of India reveal that hysterectomised women are from vulnerable communities and have been forced by the private medical practitioners into unnecessary surgeries to make money (HRLN 2012; McGivering, 2013; Mamidi \& Mamidi 2005; Prakasamma 2002; Srivastava 2010; Yadavar 2013;).

Often private hospitals resorted to complete removal of the uterus and ovaries adversely affecting the reproductive lives of rural poor women who approach with routine complaints such as abdominal pain, white discharge, excessive bleeding and irregular menstrual cycle that are curable by simple methods.

High incidence of hysterectomies as a result of it becoming the major source of business for private hospitals is evident from super escalation of the trend with the introduction of state health insurance schemes reimbursing indiscriminate surgeries performed by the private hospitals. Further, the profiteering motive driving the hospitals into abuse of health insurance schemes is also evident with sharp decline in number of hysterectomies after new guidelines were introduced by Rajiv Aarogyasri in Andhra Pradesh to arrest indiscriminate hysterectomies owing to pressure of the civil society. Hysterectomies that reached a peak of 12,211 surgeries in 2009-10 and 12,212 in 2009-10 claiming reimbursement of Rs 150 million and 390 million respectively under the Aarogyasri dropped to 4,943 in 2011-12 costing Rs 140 million (Devulapalli, 2012).

The flourishing business for many nursing homes in the state became so detrimental to the public that "as many as $70 \%$ of the total surgeries in small town nursing homes are hysterectomies" with Aarogyasri Health Care Trust "freely clearing the claims focusing more on number of surgeries than the reason why they were performed on such a large number of women" (Devulapalli, 2012). Hysterectomies in private hospitals were rolled back in July 2012 but tens of thousands of vulnerable women became victims of the abuse of state sponsored health insurance schemes abused by the profiteering private hospitals.

Table 1. Number of hysterectomies performed and cost under Rajiv Aarogyasri Community Health Insurance Scheme in Andhra Pradesh

\begin{tabular}{|c|c|c|c|}
\hline Year & Amount spent INR in million & Number of hysterectomies & Average cost of hysterectomy (INR) \\
\hline $2008-09$ & 150 & 10,334 & 14515 \\
\hline $2009-10$ & 390 & 12,212 & 31936 \\
\hline $2010-11$ & 190 & 6,189 & 30700 \\
\hline $2011-12$ & 140 & 4,943 & 28323 \\
\hline
\end{tabular}




\section{Medak Case Study}

The growing problem of women from vulnerable sections becoming victims of violence and violation of human rights is discussed with field data from Medak district of South India where civil societies have been fighting against assault on women's sexual and reproductive health rights by private healthcare that made poor women into objects for exploitation. Forced hysterectomies in Medak district reflect the growing trend of private healthcare becoming a major threat to the SRHRs of poor women.

Hysterectomies are performed indiscriminately for forcing women to become victims of health disorders of severe nature in early age (Kameswari \& Vinjamuri, 2013; Mamidi \& Mamidi, 2005; Moyna, 2010). Women, especially those belonging to vulnerable communities are increasingly robbed off their bodies and life by conniving mechanisms developed into an institution by the greedy medical practitioners supported by health insurance policies supported by the government. Data from field studies in Andhra Pradesh between 2002 and 2011 also indicates most of the hysterectomies performed in private hospitals (Table. 2).

"All the women National Doordarshan television ( NDTV) spoke to said they had not gone to a government health care centre because they did not get any care there. So the women got pushed to private doctors, who then performed the surgeries", observed NDTV report (Sudhir, 2010).

\section{Easy Targets for Hysterectomies}

The women undergoing hysterectomies mostly illiterate, inhabitants of remote villages having little access to alternative health care institutions or advice, and have little scope for informed choices. While female illiteracy of all ages constituted 49.71 \% in Andhra Pradesh in 2001, the illiterate hysterectomised women among reproductive age constituted more than three fourths. Illiterate women were targeted for coerced hysterectomies. "Most patients were from the Lambada tribal community, poor and illiterate" in Medak district that sparked off debate on coerced hysterectomies (Antony, 2012). They have little access to approach any other physicians for a second opinion according to a study in Kowdipally mandal of Medak district covering 728 hysterectomised women in 2005 (Mamidi \& Mamidi, 2005). Another study conducted by Life-HRG Group in 2009- 2011 in Munipally mandal of Medak district comprising 171 hysterectomised women revealed similar conditions. "There was little consideration to the terms of consent given that the majority of women were from the lower income group and illiterate" (Kameswari \& Vinjamuri, 2013).

Similarly women from marginalized sections constitute higher proportion among hysterectomised women. Lambada scheduled tribe women in Kowdipally mandal constituted $35.3 \%$ of hysterectomised women significantly higher than their numeric presence of $17 \%$ of total population (Mamidi $\&$ Mamidi, 2005). Narratives of the volunteers and ethnographic account of the women victims from Lambada tribe and other vulnerable castes clearly identify their poverty, illiteracy and status in the overall social fabric of the Indian society that targeted them for coerced hysterectomies. Here are some of the narratives of these women.

\section{Insurance to Suffer Early and Longer}

"I am robbed of my life and my body. I did not know I was buying death. I thought the operation was going to relieve me from regular pain and the death from cancer. I am cheated and ruined. I suffer more now", complained Lakshmi, aged 35.

Reason for surgery is any small complaint from stomach pain to cyst. Normal problems like personal hygiene or white discharge is the most popular reason. CARPED study of 728 affected women in Kowdipally mandal revealed $72.94 \%$ of them had complaints of bleeding or white discharge, followed by stomach pain $(12.77 \%)$, cysts $(4.26 \%)$, uterus erosion $(3.12 \%)$, and other complaints $(7.01 \%)$.

"They said you have sores on your ulcer. They asked us to come next day. They asked us for money and we took the money and went to them. Along with uterus they removed the appendix also. I don't have children" told another woman (TV9, 2010). Similar story of women suffering from routine ailments were scared to get operated immediately or would die.

Table 2. Distribution of Respondents by Type of Hospital for Hysterectomy

\begin{tabular}{|c|c|c|c|c|}
\hline \multirow{2}{*}{ Type of hospital } & \multicolumn{2}{|c|}{ CARPED study (2005) } & \multicolumn{2}{c|}{ Life HRG Study (2013) } \\
\cline { 2 - 5 } & No. of women & Percentage & No. of women & Percentage \\
\hline Private hospitals & 706 & 96.98 & 163 & 95.32 \\
\hline Government hospitals & 22 & 3.02 & 8 & 4.68 \\
\hline Total & 728 & 100 & 171 & 100 \\
\hline
\end{tabular}


Table 3. Distribution of Hysterectomised Women by Age

\begin{tabular}{|c|c|c|c|c|}
\hline \multirow{2}{*}{ Age of women } & \multicolumn{2}{|c|}{ CARPED study (2005) } & \multicolumn{2}{c|}{ Life HRG Study (2013) } \\
\cline { 2 - 5 } & $\begin{array}{c}\text { No. of } \\
\text { women }\end{array}$ & Percentage & No. of women & Percentage \\
\hline$<30$ years & 254 & 34.89 & 92 & 59.74 \\
\hline 31 to 35 years & 212 & 29.12 & 42 & 27.27 \\
\hline 36 to 40 years & 121 & 16.62 & 20 & 12.99 \\
\hline 41 to 50 years & 106 & 14.56 & & \\
\hline$>50$ & 35 & 4.81 & & 100 \\
\hline Total & 728 & 100 & 154 & \\
\hline
\end{tabular}

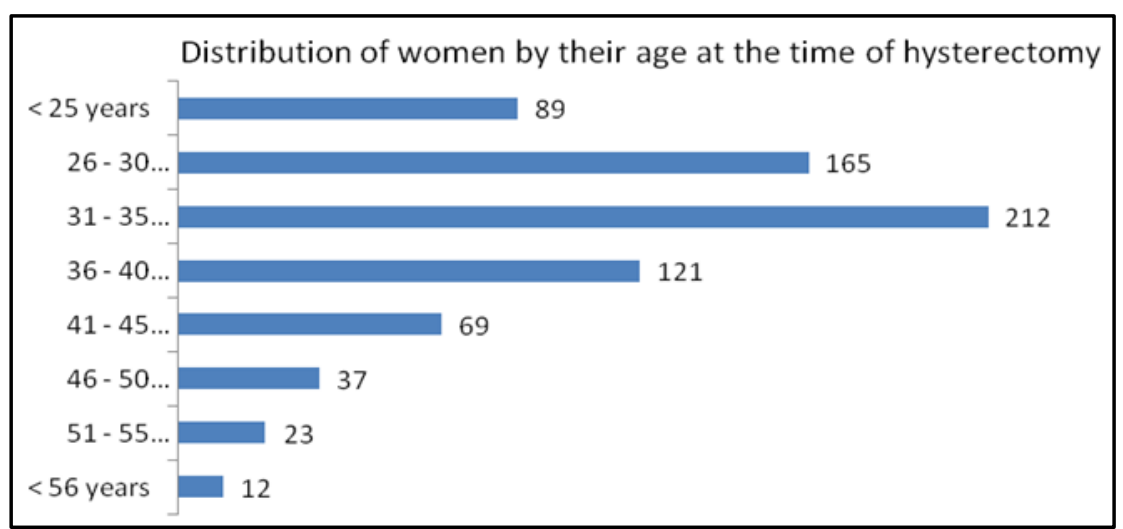

Figure 1. Distribution of hysterectomised women by age in Kowdipally mandal

Too Early To Suffer Old Age Problems for Life

Average age of the hysterectomised women was 28.5 years in Medak study (Life HRG, 2013). Women in twenties and thirties are victims of forced hysterectomies. Hysterectomised women suffer multiple tragedies and varying length of years depending on their age. Suffering side effects includes poorer health and dependence on medication, inability to contribute to household incomes, inability to provide normal attention to the needs of growing children. Affected women not only feel they are a drain on the family's meager earnings, but also worried of suffering the loss of health for years and decades ahead.

Data reveals that more and younger women are affected by hysterectomies in the district. Risk of hysterectomy that women may have in forties or fifties is the reality for poor women in thirties or even earlier. Kowdipally and Munipally mandals data indicates significant rise of hysterectomy among women below 30 years between 2005 and 2011. Hysterectomised women below 30 years age increased from $34.89 \%$ to $59.74 \%$ from 2005 to 2011 in the district. It is shocking to observe that early hysterectomies have become most common after introduction of Arogyasri community health insurance which has rewarded private hospitals to target every poor woman into a patient for surgery. Misconception that it is free and fear that it is essential for the women to remain alive resulted in increasing number of women and increasing number of younger women to be victimized. Table. 3 provides age wise details of hysterectomised women in 2005 and 2011.

Further detailed distribution of hysterectomised women by age in CARPED 2005 study reveals that $19.37 \%$ women were aged between forties and fifties. Market driven healthcare over the years resulted in increasing number of women suffer menopause at lower ages (see Fig.1 for details).

\section{Shattering Costs and Additional Insecurities}

"Now I cannot earn anything. I cannot work in the field for a few hours like I used to do in the past. I also need money for medicines regularly. I have become a burden to my family. How long my husband would tolerate me, I don't know", says Sharada, aged 35.

Sharada is not sure when her husband would abandon her. Contrary to 'popular belief' that once a small operation is done all problems will be kept at a distance, hysterectomies are not small operations and never keeping other problems away. It is a very expensive surgery and drains the household's meager financial resources. In some cases the women have become indebted because of the expenses on surgery. Expenditure of Rs 10,000 to 15,000 for rural poor households is major catastrophe for the affected family. Some of these families have been forced to sell their assets. "We had to sell our cattle to mobilize money for the operation. That was our only asset", says Shyamala of 32 
years old. Besides the pain of affected woman suffering from side effects and unable to undertake any domestic chores, it is a significant loss for the family with one of the members becoming incapable of earning anything from physical work or contributing to the labour required for household farming.

"We have problem to meet our needs and we make every effort to all domestic needs after discussing all options. Now we have more problems and bigger problems with lesser earning hands and increased costs. My poor health and cost of medicines figures up in the discussions as another reason for the problem. I feel sick and guilty," says Shanti aged 31 and mother of two school going children.

Large number of respondents has spent more than Rs 10,000 each. While $21.7 \%$ respondents have spent less than Rs 10,000 and $88.3 \%$ respondents have spent anything from Rs 10,000 to Rs 17,000 each.

"Government doctors did not offer any solution. Not even an injection. So I went to a private doctor. The operation cost me Rs. 20,000. We had to take a loan for it," says Roopli aged 20s of Lambada tribal community from Kowdipally mandal. She is mother of two children and already hit menopause (Sudhir, 2010).

At the community level it is colossal loss from the rural poor. Millions of rupees of poor women are robbed off in the name of surgery by greedy doctors. There are also indirect expenses and long term costs. Often these women are not able to undertake physical work and lose their earnings from wage labor. More than 6 million INR was spent by affected households of Kowdipally mandal on surgeries, besides considerable amounts on travel, medicines, etc during the surgery. Further they are compelled to lose their earnings and spend additionally on their medicines all the remaining lives. Table. 4 provides the costs incurred by women prior to Aarogyasri scheme.

"The cost of maintaining the health of a woman who had undergone hysterectomy with medicines and supplements is Rs.18,250 a year," according Life HRG study on the surgery's impact on women in Medak district in 2011 (Yadavar, 2013). That's a lifelong burden that innocent women have to suffer for availing once a 'free' hysterectomy from unethical traders in healthcare.

\section{Multiple suffering and hardships}

"What do I do, I don't feel like earlier and cannot keep my husband happy. And I cannot have a son. He married another woman" told Lakshmamma, aged 37.

Affected women suffer several disadvantages and hardships owing to hysterectomy and subsequent physical and psychological impact. Some of them suffer from depression, loss of libido, guilt of being useless or a burden, being 'barren' to bear another child, loss of self esteem and family disorganization.

Sometimes the tragedy is not only limited to the affected woman, but also affecting the whole family. Children and spouses are also affected by early menopause. Women after hysterectomy faced domestic violence over sexual issues, and their spouse had extra-marital affairs (Yadavar, 2013).

"My daughter stopped going to school to help in household chores, because I am not able to handle myself", says Sita aged 30. These women have children to be taken care of besides helping in the household work. Around half of the hysterectomised women (53.3\%) have 3 to 4 children while $29.7 \%$ have one or two children. They find it difficult to attend to the children with failing health. Regular complaints of poor health and loss of libido has been complained by some women as reason for neglect by their spouse. Special preference for boy or a girl child makes hysterectomised women inadequate for losing the ability to bear another child. Some women have been deserted by the husband on the pretext that she cannot have another child, especially a boy child. Most of the women have a male child. However, $13.2 \%$ women did not have a male child and $21 \%$ did not have girl child.

Several women suffer trauma of losing a normal life and being treated as an incomplete person or a sick person. "It's better to die than suffer this pain", says Shobha, aged 29.

Civil society is faced with the challenge: What will ensure recovery of the losses from insurance violence unleashed on such large number of women?

Table 4. Cost of Hysterectomies in Kowdipally

\begin{tabular}{|c|c|c|}
\hline Total cost of operation (INR) & No of respondents & Percentage of total \\
\hline $1-2500$ & 4 & .5 \\
\hline $2501-5000$ & 20 & 2.7 \\
\hline $5001-7500$ & 135 & 18.5 \\
\hline $7501-10000$ & 457 & 62.8 \\
\hline $10001-12500$ & 89 & 12.2 \\
\hline $12501-15000$ & 21 & 2.9 \\
\hline $15001-17000$ & 2 & .3 \\
\hline Total & 728 & 100.0 \\
\hline
\end{tabular}




\section{Role of Civil Society}

Healthcare concerns are gaining attention of the civil society and authorities since a decade with growing privatization of healthcare in India. Civil society struggles relate to demand for effective state role in ensuring access to healthcare for disadvantaged sections, ethics in healthcare, arresting corporatization of healthcare, protection of women's SRHRs. These struggles primarily emphasize right to health, right to informed choices, consent of the patient and regulatory role of the state. Interventions of the civil society are at different levels and forms in parts of the country. Threat of private healthcare to human rights of this scale is a new challenge posed to the civil society in India.

Campaign against forced hysterectomies has become a national issue compelling attention of the media, authorities and civil society. Civil society has been fighting forced hysterectomies and the abuse of state sponsored health insurance schemes. The struggle is primarily to protect poor women from exploitation by the profit driven private healthcare system which is supported by the state. There are several groups involved in actively campaigning for regulation of private healthcare systems which pose serious threat to the life and rights of citizens, especially the poor and women.

\subsection{Transformation of Local Campaign into National Issue}

Forced hysterectomies were flagged as an issue of serious concern in Medak district in 2005. Centre for Action Research \& People's Development's (CARPED) study of 728 hysterectomies women in Kowdipally mandal drew attention of varied sections to the unprecedented incidence levels and coercive methods of private hospitals to make money. Evidence based advocacy supported mass campaign in the area against forced hysterectomies, sensitization of women groups not to be cheated into hysterectomies and demanding state involvement to arrest forced hysterectomies. Public hearings were held with hundreds of hysterectomised women to voice their concerns and problems before elected representatives, authorities, medical experts and human rights defenders. Medak focused field interventions of community sensitization, awareness and raids by authorities on private hospitals involved in indiscriminate hysterectomies and advocacy were continuous news shared widely through regional and English media from 2005 to 2009. The problem of hysterectomies was not specific to Medak district alone, but there was continuous debate about Medak hysterectomies at different levels due to the concerted action of the local NGO. Local NGO highlighted the role of insurance, gender bias, in addition to bringing forth the ethical issues in the medical profession. Other NGOs in the state also started raising the issue in the subsequent years.

Introduction of Aarogyasri scheme in 2007 contributed to manifold increase in hysterectomies in Andhra Pradesh. With growing attention there were several members of medical fraternity, women empowerment groups and other NGOs intensified the campaign. Two more studies were conducted on hysterectomies in Andhra Pradesh - Andhra Pradesh Mahila Samatha Society comprising 1097 sample in five districts in 2009, and Life -Health Reinforcement Group comprising 171 sample in Medak district in 2010. Anveshi, Centre for World Solidarity and other groups also strengthened the campaign against forced hysterectomies under Aarogyasri scheme. With growing pressure from media and civil society the government started arresting indiscriminate hysterectomies in the Aarogyasri scheme and issued instructions on January 18, 2011 and July 17, 2012. Currently government hospitals only are entitled to perform hysterectomies under the scheme to ensure that only genuine cases undergo the procedure. From a peak of 12,212 hysterectomy cases in 2009-10 it declined to 4,943 in 2011-12. Several thousand women are saved from becoming victims of unnecessary hysterectomies.

Campaign in Andhra Pradesh became a national issue with several national TV channels and newspapers and journals highlighting the ill effects health insurance schemes. Satyameva Jayate programme on Star TV with popular Hindi cine hero Amir Khan in the episode titled "Does Healthcare Need Healing?" stressed the need to regulate forced hysterectomies like what is rampant in Medak district (Satyameva Jayate, 2012).

5.2 Strength of the campaign against violation women's SRHRs

NGOs, experts and authorities noticed the potential of misuse of health insurance schemes. Rajiv Gandhi Jeevandayee Arogya Yojana of Maharashtra government launched on 2 July 2012 has excluded hysterectomies in the scheme based on the learnings from Andhra Pradesh. Hysterectomies became matter of scam and controversy in Chhattisgarh, Bihar, and Rajasthan states under RSBY in 2012. Central Minister for Health and Family Welfare initiated probe into allegations of misuse in Bihar in August 2012 (Times of India, 2012) and cancelled registration of nine doctors were suspended for conducting hysterectomies without proper test in Chhattisgarh. Central government has also directed all state nodal agencies of RSBY that approval from the insurance company concerned is mandatory for hysterectomies performed on women under age 40 (Yadavar, 2013). Civil society in Chhattisgarh took the matter of forced hysterectomies to the notice of the National Human Rights Commission which led to cancellation of licenses of 22 private hospitals. International NGOs like Oxfam has started the campaign against hysterectomies in these states in 2013.

Human Rights Law Network has initiated Public Interest Litigation (PIL) in the Supreme Court of India to ensure compensation for the victims of unethical and unlawful hysterectomies in Bihar, Chhattisgarh, and Rajasthan. The Supreme Court has issued notices on 18 March 2013 to respondent state governments in a recent case which 
suggests that the storm against forced hysterectomies is gaining all India prominence.

\section{Conclusions}

There is significant progress in identifying and challenging the coerced hysterectomies in India. However, the discourse is limited to certain procedures, coercive surgeries, compensating the victims, and abuses of certain health insurance schemes. Focus is largely on arresting abuses in government schemes. Accountability of the medical fraternity is also a matter of concern in a society where doctors are seen as saviors, but in practice are perpetuating morbidity and mortality and exploitation.

As researchers we believe that there are several issues that need attention to locate healthcare in human rights perspective and development that is pro-poor. Prominent issues that require further action research are:

- How to arrest unethical trends of commercialization of healthcare and unprecedented incidence of hysterectomies, caesarian deliveries, appendicitis etc?

- How to make health policy shift its focus on tertiary care to effective primary and secondary care to prevent from becoming seriously ill?

- How to ensuring policy environment conducive for effective prevention of illness, morbidity and mortality to attain global standards?

- How to make private healthcare accountable and transparent?

Finally for a third world country like India a charter of citizens and patients that will protect their right to health and well being and awareness promotion programmes that assist real informed choices and consents for surgery are very important.

Development, safety nets and welfare measures could become serious threat to the human rights if governance measures are weak with regard to the game plan of business. We suggest that this is a challenge in several developing countries and by the same token the MDGs could be jeopardized if the governance is tainted and laden with corrupt practices. There are often suggestions that human rights discourse ought to sit beyond economic indicators of progress and ensure well being. Many questions shroud the disturbing state of healthcare and increasing violation of human rights and more particularly sexual and reproductive health rights of vulnerable women. Without radical change in the situation the 'development' models in health sector potentially make the poor further alienated, exploited and victimized by the public-private partnership models with state sponsorship. Further research and interventions in that direction would have significant outcomes in future.

\section{REFERENCES}

Antony, K.R. (2012). Put errant doctors on the mat, The Hindu, August 22, 2012

http://www.thehindu.com/opinion/op-ed/put-errant-doctors-on-the -mat/article3804283.ece

Choudhury, T. (2012). Health insurance in rural India: RSBY, a saviour for the poor? Modern Medicare, April 30, 2012 http://modernmedicare.co.in/articles/health-insurance-in-rural-indi a-rsby-a-saviour-for-the-poor/

Colekessian, A. (2013). Violating Women's Rights: Forced Sterilization, Population Control and HIV/AIDS http://www.intdev communities.com/full.php?ID=702\#sthash.65gTBv2p.85wjiThD.d puf

Devulapalli, R. (2012). Secret behind rash of hysterectomies out, Times of India, September 28, 2012. http://articles.timesofindia.in diatimes.com/2012-09-28/hyderabad/34147487_1_hysterectomieslaparoscopic-aarogyasri-trust

Human Rights Law Network. (2013). From The Field to the Judge's Bench: Developing Litigation Strategies to Improve the Lives of Women, New Delhihttp://www.hrln.org/hrln/images/stories/pdf/N ational $\% 20$ Consultation $\% 20$ Report $\% 20-\% 20$ To\%20Print.pdf

Hysterectomy Association- UK http://www.hysterectomy-associati on.org.uk/

Kameswari, S.V., \& Vinjamuri, P. (2013). Medical Ethics: A case study of Hysterectomy in Andhra Pradesh, Life - Health Reinforcement Group, Hyderabad. http://kicsforum.net/kics/setdev /hysterectomy-ethics-in-S-T-for-setdev-final-1.pdf

Kannan, K.P., Thankappan, K.R., Raman, K.V., Aravindan, K.P. (1991). Health and development in rural Kerala: A study of the linkages between socioeconomic status and health status. Trivandrum: Kerala Sastra Sahitya Parishad.

Mamidi, M.B., \& Mamidi, S.C. (2005). Hysterectomies in Kowdipally Mandal, Medak district of South India, Discussion Papers - 8, Centre for Action Research and People's Development, Hyderabad

Mathews, S.M. (2012). A Critical Analysis of Arogyasri Health Insurance Scheme (A Project of Andhra Pradesh State Government) http://sajitsj.blogspot.in/2012/02/critical-analysis-of-arogyasri-heal th.html

McGivering, J, (2013), BBC News. http://www.bbc.co.uk/news/m agazine-21297606 retrieved on 6th February 2013

Ministry of Health and Family Welfare, GOI. (2005). Financing and Delivery of Health Care Services in India- National Commission on Macroeconomics and Health, New Delhi p.54 http://www.who.int/macrohealth/action/Background $\% 20$ Papers $\% 2$ Oreport.pdf

Ministry of Health and Family Welfare- GOI. (2009). National Health Accounts: India, 2004-05, New Delhi. http://planningcom mission.nic.in/reports/genrep/health/National_Health_Account_04 _05.pdf

Moyna. (2010). Menopaused 20-somethings, Down to Earth, 15 June, 2010 http://www.downtoearth.org.in/node/668

Nagulapalli, S., \& Rokkam, S.R. (2013). An analysis of Rajiv Aarogyasri Community Health Insurance Scheme, AHCT working paper \#1 http://www.aarogyasri.gov.in/ASRI/EXT_IMAGES/docu ments/ASRI_Analysis.pdf

Planning Commission of India. (2011). High Level Expert Group Report on Universal Health Coverage for India, New Delhi. 
http://planningcommission.nic.in/reports/genrep/rep_uhc0812.pdf

Prakasamma, M. (2002). Study of Operative Interventions in Women- Hysterectomy, Academy for Nursing Studies, Hyderabad.

Prasad, N.P., \& Raghavendra, P. (2012). "Healthcare Models in the Era of Medical Neo-liberalism: A Study of Aarogyasri in Andhra Pradesh", Economic and Political Weekly, October 27, 2012 vol xlvii no 43, p 118-126

Satyameva Jayate. (2012). "Coerced into hysterectomies" in Every Life Is Precious- Episode 04: Does Healthcare Need Healing? Satyameva Jayate, May 27, $2102 \mathrm{http} / /$ www.satyamevjayate.in/iss ue04/videos/p4jHKyDTPx8/

Shukla, Rajan, Shatrugna, V., \& Srivatsan, R. (2011). “Aarogyasri Health Care Model: Advantage Private Sector", Economic \& Political Weekly, Vol XLVI (49), December 3, pp 38-42.

Srivastava, R. (2005). Greedy doctors con 600 tribal women into surgery, Mumbai Mirror, 17 September, 2005

http://www.carped.org/attachments/article/30/Greedydoctors.pdf

Srivastava, R. (2010). The uterus snatchers of Andhra, Times of India, Jul 31, $2010 \mathrm{http}: / /$ articles.timesofindia.indiatimes.com/201 0-07-31/india/28301543_1_hysterectomy-women-in-rural-pockets -doctors-gain

Sudarshan, H. (2003). The epidemic of corruption in health services. Presentation at the Institute for Health Systems, Hyderabad, India, August 18, 2003.

Sudhir, U. (2010). Womb removal: Andhra's big medical scandal, NDTV, August 27, 2010 http://www.ndtv.com/article/india/womb -removal-andhra-s-big-medical-scandal-47462

Supreme Court Judgment, the PIL Narendra Gupta vs. Union of India and Ors., (W. P. (C) 131/2013)

(ttp://www.hrln.org/hrln/reproductive-rights/pils-a-cases/1264-sup reme-court-issues-notices-to-rajasthan-chhattisgarh-and-bihar-stat e-governments-in-petition-on-unethical-and-unlawful-hysterectom ies.html

The New Indian Express. (2013). Arogyasri scheme: Where does the buck stop? The New Indian Express, April 5, 2013 http://newindianexpress.com/states/andhra_pradesh/article153120 2.ece

Times of India (2012). Probe initiated into forced hysterectomy in Bihar, Times of India, Aug 29, 2012

http://articles.timesofindia.indiatimes.com/2012-08-29/patna/3347 5382_1_hysterectomy-bihar-government-private-hospitals

TV9. (2010). Illegal hysterectomies, TV9, September 6, 2010 http://www.youtube.com/watch?v=K1LeCwD2PD4

UNHR. (2008). Claiming the Millennium Development Goals: A human rights approach, United Nations High Commissioner for Human Rights, United Nations, New York and Geneva.

United Nations Report of the Fourth World Conference on Women, 1995, Beijing ( 96.IV.13)

Vijay, G. (2012). "The Business of Health Care and the Challenge of Health Security: The Case of Aarogyasri Health Insurance Programme in Andhra Pradesh" in Kannan, K. P., \& Jan Breman, The Long Road to Social Security, OUP, New Delhi.

Yadavar, S. (2013). The Great Uterus Robbery - Wombs and the Wolves, The Week, April 15, 2013 http://week.manoramaonline.c $\mathrm{om} /$ cgi-bin/MMOnline.dll/portal/ep/theWeekContent.do?contentId $=13857015 \&$ programId $=1073755753 \&$ tabId $=13 \&$ categoryId $=-19$ 9981

Yellaiah, J. (2013). Health Insurance in India: Rajiv Aarogyasri Health Insurance Scheme in Andhra Pradesh, IOSR Journal of Humanities and Social Science (IOSR-JHSS), Volume 8, Issue 1 (Jan. - Feb. 2013), PP 7-14 http://www.iosrjournals.org/iosr-jhss/p apers/Vol8-issue1/B0810714.pdf 